\section{EMBRYRIDDLE}

Aeronautical University

SCHOLARLY COMMONS
Journal of Aviation/Aerospace

Education \& Research

Volume 9

Number 2 JAAER Winter 2000

Article 3

Winter 2000

\title{
Collegiate Aviation Maintenance Programs: Focus on Quality or Safety?
}

Alan J. Stolzer

stolzera@erau.edu

Follow this and additional works at: https://commons.erau.edu/jaaer

\section{Scholarly Commons Citation}

Stolzer, A. J. (2000). Collegiate Aviation Maintenance Programs: Focus on Quality or Safety?. Journal of Aviation/Aerospace Education \& Research, 9(2). https://doi.org/10.15394/jaaer.2000.1246

This Article is brought to you for free and open access by the Journals at Scholarly Commons. It has been accepted for inclusion in Journal of Aviation/Aerospace Education \& Research by an authorized administrator of Scholarly Commons. For more information, please contact commons@erau.edu. 


\title{
COLLEGIATE AVIATION MAINTENANCE PROGRAMS: FOCUS ON QUALITY OR SAFETY?
}

\begin{abstract}
Alan J. Stolzer
Safety is a prime concern of managers of collegiate aviation maintenance facilities, but often the 'safety' program developed is not as effective as the managers desire. A literature review was conducted to explore the relationship between quality and safety programs, and to determine whether coupling a safety program with a comprehensive quality program might produce better results. Strategies such as behavioral sampling, fishbone diagrams, flow charts, and statistical process control (SPC) - all techniques used extensively in the quality profession - can reveal system flaws and lead to continuous improvement. The literature review suggests that the implementation of a quality program has the potential to improve both safety and the process and efficiency of the maintenance facility in a structured, continuous manner.
\end{abstract}

\section{Glossary}

Fishbone Diagrams - Also known as a 'cause and effect' diagram. This is a tool designed to assist in focusing on the cause of the problem rather than the problem itself.

Flowcharts - A flowchart is a diagram that illustrates the activities in a process. Flowcharts are useful tools to improve a process. ISO 9000 - Entitled "Quality Management and Quality Assurance Standards - Guidelines for Selection and Use," ISO 9000 standards were initially published in 1987. Essentially the standards are generic in nature and represent an international consensus on good management practices.

Kaizen - Kaizen is a Japanese term that means continuous improvement. There are many techniques used to seek Kaizen, including team problem solving, quality circles, and others.

Quality - The unrelenting pursuit of continuous improvement throughout an organization which is realized by accessing and utilizing the concerted knowledge and experience of managers and employees at all levels of an organization in a data-driven, cooperative, coordinated, and systematic approach" (Ebrahimpour, Withers, \& Hikmet, 1997).

Quality System - Quality system is a broad term referring to the resources, structure, procedure and process within the organization needed to implement a quality program (Peach, 1995).

SPC - Statistical Process Control (SPC) - Data collection and analysis through tools such as frequency distributions, Pareto principle, Ishikawa diagram, Shewhart control chart, and others, and application of the concept of process capability (Juran, 1999).

Total Quality Management (TQM) - A management approach of an organization, centered on quality, and based on the participation of all its members.

Six Sigma - Six sigma is an analytical process involving intensive data gathering designed to anticipate and use a variety of quality engineering tools to solve problems. Six sigma means having less than 4 defects (3.4) in one million opportunities. 
Collegiate aviation maintenance facilities maintain the fleets of aircraft used in flight training degree programs. These facilities may range in size from many employees and airplanes to few of either, but they have several things in common. The work of the maintenance operation is highly technical, and there is very little margin for error. Errors on the part of maintenance systems and workers can, quite simply, cause property damage, injury or death. Thus, the subject of safety in collegiate aviation maintenance programs is one that evokes considerable discussion.

No one would deny that safety in inspecting, maintaining and overhauling aircraft and components parts is critical to the success of the collegiate aviation program. To that end, many maintenance managers have developed safety programs for their facilities. These programs vary from several commonsense rules to very elaborate, sophisticated policies and procedures manuals, briefings, and seminars. Most are quite effective, but none is likely as good as it can be.

Whether or not managers can describe what they do using terminology common in the quality field, maintenance facility managers and workers are practicing many of the quality concepts. Terms such as total quality management (TQM), benchmarking, continuous improvement, Kaizen, quality improvement, and others, are indicative of the kinds of things that should be happening in maintenance facilities. Given that most maintenance managers think about safety specifically and about quality in general, the question is: Would there be an advantage to formalizing a quality program using accepted standards that also embraces safety? Thus, the purpose of this literature review is to provide decision-makers information so that they can consider the development and implementation of quality standards in the collegiate aviation maintenance environment as a means of improving safety and quality in an inclusive, systematic, and continuous program. In doing this, several issues will be discussed: aviation and quality; benefits of quality; and standards.

\section{Research Methodology}

The literature review was begun by searching several business related databases such as ProQuest, MERLIN (Missouri Education and Research Libraries Information Network), and FirstSearch, for relevant articles written in the past several years. The search was limited to more recent articles since ample material was available and older articles would likely not reflect recent changes in standards and applications. In these databases, several hundred articles were located that referenced the topic of 'quality standards AND safety', 'quality assurance AND safety', 'registration AND performance', 'benefits quality standards', 'advantages for quality standards', and other similar search terms. Approximately 110 abstracts were determined to be relevant to the topic. Full text articles were available for 73 of the abstracts and all were read in detail. Of the 73 full text articles, 21 were deemed valuable to understanding the relationship of quality and safety programs, and these provided the basis for this literature review.

\section{Results}

The literature discusses the interrelationship of safety and quality, aviation and quality standards programs, and the benefits of implementing quality programs.

\section{Safety and Quality}

One of the fundamental issues that managers must address is what they are attempting to achieve with a safety program. Unfortunately, many companies still regard safety programs as a collection of employee mandates designed to prevent major catastrophes (Pollock, 1995). Studies have shown that these types of safety programs have reached a plateau in their effectiveness largely as a result of their focus on technical requirements and short-term issues, and because they are not integrated organization-wide. These are termed complianceoriented programs. The alternative to these are welldeveloped quality-style safety programs which promote excellence and continuous improvement (Weinstein, 1996). It should be stressed that a quality system is not merely a manual or handbook of some sort; it is the organizational structure, procedures, processes and resources needed to implement quality management (Peach, 1995). The term safety could be substituted for quality in this definition, and it is in this program model that the similarities with quality systems becomes apparent.

The literature is replete with expert discussion on the interrelationship of safety and quality. An analysis of the criteria for the Malcolm Baldrige National Quality Award (MBNQA) for an examination of this relationship underscores this point. The criteria include leadership, strategic planning, customer and market focus, information and analysis, human resource focus, process management, and business results (National Institute of Standards and Technology, 1997). Considering the first of these criteria only, the leadership of the managers is a critical component of a quality system. Leaders must create values, direction, performance 
expectations, and loyalty for a quality system to be successful. Safety programs require similar leadership qualities. Managers set the tone for safety systems by demonstrating the value of established safety practices, communicating goals and expectations, and conducting reviews and audits to determine achievement (Warrack \& Sinha, 1999). Similar arguments can be made to show the applicability of the remaining Baldrige criteria to both quality and safety.

Besides the common comparisons to criteria such as MBNQA's, authors have focused on the need for safety to be a core value of the organization, which includes employee involvement in the program, and the use of teams and committees. Additionally, measurement is a tenet of TQM that can be applied to safety. Establishing a benchmark for safety is an important way to assess the improvement of an organization in its safety efforts, and to identify areas that need to be addressed. The baseline from which this normally begins is established from accident reports, workers' compensation claims, medical records, and safety inspection reports (Pollock, 1995).

The Southern California Safety Institute (SCSI) makes a strong statement about the connection between safety and quality. In their course description for Operational Risk Management, SCSI states, "Operational Risk Management formulates this approach by implementing a logic-driven process to analyze the degree of risk associated with identified hazards, recommending Risk-based solutions, and monitoring the effectiveness of these solutions. Does this appear similar to Quality Programs implemented successfully by World Class Companies? It should. Operational Risk Management successfully integrates quality with safety program management. It is no longer safety versus the mission. Safety and quality must be totally integrated with the mission" (SCSI, 2000).

Quality management and safety both require not only employee involvement, but also employee training. Aviation maintenance managers who have a safety program must educate their employees in the expectations regarding safety, the policies and practices, and resources and tools available to them to solve safety problems.

Safety and quality systems must be so interwoven into the corporate culture that it is simply regarded as 'the way business is done' (Pollock, 1995). An organization whose safety program consists solely of a manual that sits on a shelf does not have an effective safety program. The same can be said of a quality system. For either to be successful, they must be implemented over time, with interim goals established and evaluated, preferably by employees and in teams, and embraced from the top to the bottom of the organization.

Both safety and quality programs have a positive effect on the bottom line of an organization and are accepted as good business practices. Integration of these together and into the culture of the organization is required in order to ensure their sustainability and the continuous improvement sought by management (Warrack \& Sinha, 1999).

Like quality, a proactive safety system is better than a reactive one. A system that focuses on performing all activities right the first time will be more effective than one that continually analyzes accidents or mishaps in order to prevent them in the future (Manzella, 1997). Instead of accident investigation, 'upstream' strategies such as behavioral sampling, fishbone diagrams, flow charts, and statistical process control (SPC) - all techniques used extensively in quality systems - can reveal system flaws and lead to continuous improvement (Peterson, 1994). In the case of SPC-based quality improvement, management is guided by measurements of upstream factors that are predictive of defects rather than product defects (downstream factors). When this model is applied to safety, the upstream factors are safety-related behaviors while the downstream factors are accidents (Krause, 1993).

\section{Aviation and Quality}

There has been an abundance of literature discussing the trend of companies moving toward quality system programs, especially during the last several years. But unfortunately, the government agency with oversight responsibility for aviation, the Federal Aviation Administration (FAA), has not been a leader in that movement. In fact, the requirement of an Inspection Procedures Manual has been the extent of the FAA's encouragement for development of a quality program for repair stations (Garetson, 1999). However, as a result of inspections following some well-publicized aircraft accidents, the FAA recently joined the campaign for quality programs. By issuing Notice of Proposed Rulemaking (NPRM) 99-09 on June 21,1999 , the FAA is attempting to improve the repair station certificate holder's effectiveness in managing its procedures, training, and inspection programs. Quoting from the NPRM (Federal Aviation Administration, 1999):

After reviewing the success of quality assurance and quality monitoring systems, the FAA has determined 
that quality assurance systems are necessary to ensure that maintenance, preventive maintenance or alterations (including the maintenance and alterations performed by a repair station's contractors) are consistently performed in accordance with all applicable requirements. Thus, proposed $\S 145.201$ would require that each repair station establish a quality assurance system acceptable to the Administrator. A description of the entire quality assurance system would be included in the proposed repair station manual. Guidance on the establishment of effective quality assurance systems would be provided in advisory material published concurrently with this rule, if adopted.

Clearly, the FAA desires to move toward quality assurance programs as a means of improving safety. Many collegiate aviation programs hold FAR Part 145 repair station certificates and, thus, may be impacted by this proposed regulation.

Quality issues are a top priority for many aerospace and aviation businesses, and many of the larger companies have adopted the AS 9000 quality standard. Like the major auto manufacturers which developed the QS 9000 standards for their use, the AS9000 standard is a derivative of the universally accepted ISO 9000 quality standard used the world over. AS 9000 was developed by companies such as Boeing, McDonnell Douglas, Lockheed Martin, Northrop Grumman, GE Aircraft Engines, Pratt \& Whitney, and others. AS 9000 addresses aerospace needs in manufacturing companies, service suppliers, and regulatory bodies, and is administered by the Society of Automotive Engineers (Larson, 1999). Also participating in the development of the standard were governmental agencies such as the FAA, the Department of Defense, and the National Aviation and Space Administration (Bravener, 1997). AS 9000, titled the 'Aerospace Basic Quality System Standard', has been in existence since 1997. Companies must be AS 9000 registered in order to do business with most of the major aerospace companies. Shortly after the issuance of the standard, the FAA acknowledged that AS 9000 meets or exceeds its own expectations for a manufacturing quality control system (Bravener, 1997). While AS 9000 and the new AS9100 are aerospace quality standards, they are not considered to be at the level of ISO standards; thus, some companies require adherence to ISO 9000, supplemented by AS 9000
("Aerospace launches," 1999). This is because there is no international body with direct accreditation responsibility for AS 9000, while ISO 9000 is an international standard (Larson, 1999).

Other quality initiatives are in use in aerospace businesses. One initiative that is gaining in popularity is six sigma. Six sigma was developed by Motorola in the 1980 s to reduce defects in its manufacturing processes to 3.4 in one million, and has been extended to included business processes and service operation. The six sigma quality initiative is designed to be a disciplined, quantitative approach to improving operations in all types of businesses. The main focus is on cost and waste reduction, yield and capacity improvements, and satisfying customer needs (Juran, 1999). Raytheon Corporation is one of many that has embraced six sigma, and in 1999 began to require the quality initiative of its vendors (Velocci, 1998). Prior to its adoption, Raytheon operated in the 2-3 sigma range ( 2 sigma is 308,537 defects per million).

Whatever the approach, based on the literature it is clear that aerospace and aviation companies have embraced quality as a way of doing business. The ultimate goals remain the same for all of these - make money, reduce accidents and defects, and satisfy customers.

Benefits of Quality

In addition to a better safety program, a quality program offers many advantages and benefits, including financial incentives, improved process design, enhanced public image, improved documentation, stronger quality awareness, and improved internal operating efficiency.

Financial. While collegiate aviation maintenance programs normally are not held to the same standards of financial performance as are other business, nevertheless, these entities operate on relatively substantial budgets, are concerned with controlling costs, and are under pressure to function efficiently. Thus, it is worthwhile to note the effect that implementing quality programs ultimately has on the financial performance of a firm.

The financial impact of quality programs has been the subject of analyses in several studies. A 1999 study on the effect of TQM on financial performance clearly indicates that performance improved dramatically as a result of the implementation of TQM programs (Singhal \& Hendricks, 1999). This study was based on the analysis of factors such as the percent change in return on sales and return on assets of 600 quality award winners over two five-year periods. One of 
the five-year periods was during the implementation period of $\mathrm{TQM}$; the other was following the implementation. Interestingly, no financial decline was noted during the implementation period which was somewhat of a surprise since implementing quality programs often requires a financial investment. During the post-implementation period, the stock prices of award winners outperformed a benchmark portfolio by $34 \%$.

A second study examined the financial performance of 108 firms that had made a serious effort to implement TQM into their businesses (Easton \& Jarrell, 1998). The researchers found that these firms outperformed a sample benchmark by $16+\%$ after five years.

Another study conducted by the National Institute of Standards and Technology, which administers the Malcolm Baldrige National Quality Award, compared the publicly traded Baldrige award winners against the S\&P 500. The results were that the Baldrige winners outperformed the S\&P 500 by 2.6 to 1 ("Baldrige Index," 1999).

A 1999 study compared the performance of ISO 9000 registered firms in the electronics industry to non-registered firms, and researchers found that registered firms had a higher average profitability than those that were not registered (Simmons \& White, 1999).

A review of these studies indicates that financial performance of a company generally improves, and sometimes improves considerably, when a rigorous quality program is implemented. The studies generally focus on measures such as return on investment, return on sales, and stock value; measures which are not relevant to collegiate aviation maintenance operations. There is ample discussion in the literature on the cost of certification to a quality standard, but little discussion on the impact of a quality program on the cost of doing business.

Other Benefits. Studies and surveys have revealed several reasons why businesses embrace quality standards and registration. Benefits for small, domestic firms include improvements in the following: product or process design, product quality, public image, and documentation and quality awareness (Ebrahimpour, Withers, \& Hikmet, 1997). Zuckerman (1997) asserts that the major benefit of quality standards is the process of establishing a good quality base within a company. Another study in 1998 concluded that, while registration to the ISO 9000 standard was perceived as more beneficial to larger firms, small firms could gain much in marketing and competition areas, as well as improve internal operating efficiency (Chittenden, Poutziouris, \& Mukhtar, 1998).

Standards

Several different standards have been mentioned in this article. There are literally hundreds of standards for many different types of industries. Which standards are appropriate depends on the goals of the firm, the type of business, and whether there are regulations or other requirements mandating certain standards.

ISO 9000 standards are comprised of 20 quality system elements that range from assessments of management involvement to use of statistical process controls. ISO 9000 emphasizes achievement of process control through quality planning and goal setting, assignment of task authority and responsibility, creating systems for documenting process performance and responding to process failures. ISO 9000 standards are a series of three nested quality standards ISO 9001,9002 , and 9003 . ISO 9001 is governed by all 20 quality system elements and covers activities from design and development through production, inspection, installation or delivery, and product servicing [design and manufacture]. ISO 9002 is governed by 18 of the 20 elements, excluding design and development activities and aftermarket service [services]. ISO 9003 is governed by 12 of the 20 elements, including only quality assurance of final product inspection and testing [inspection and testing] (Anderson, Daly, \& Johnson, 1999). The intent is for the firm to select the standards appropriate for its operation.

AS 9000 is the aerospace version of ISO 9000 . AS 9000 contains all 20 quality elements of ISO 9000 , plus notations on eight of the elements and 27 other clarifications

("Aerospace launches," 1999).

TQM is not a standard but is a management approach for an organization that is focused on quality. TQM requires the participation of all members of the firm and is aimed a long term success through customer satisfaction, and to benefits to the members of the organization and to society (Peach, 1995). TQM employs a host of tools depending on the needs of the company. Importantly, it is an organization-wide approach to improve operations.

Six sigma is also not a standard, rather it is an analytical process involving data gathering designed to anticipate and bring a variety of quality engineering tools to bear on problems. Six sigma means having fewer than 4 defects (3.4) 
in one million opportunities (Juran, 1999). Many companies are embracing the concept of six sigma to improve quality.

\section{Conclusion}

This literature review is meant to encourage managers of collegiate aviation maintenance operations to consider coupling quality management to safety programs. The maintenance of aircraft is a task that requires the highest degree of precision and attention to detail. Numerous studies conclude that traditional safety programs have reached a plateau in their effectiveness. Formalizing a quality management program based on recognized standards goes beyond current Federal Aviation Administration inspectiononly requirements, though a Notice of Proposed Rulemaking (NPRM) has been published that would require the adherence to a quality assurance program for certain repair stations. The NPRM notwithstanding, internal audits or discrepancy prevention are not mandated by Federal Aviation Regulations. These are tools that can identify problems areas before they become critical issues of safety or nonconformance events. Quality standards place heavy responsibility on the role of management in the quality program, and require a system of internal audits for all processes that affect quality (Dreikorn, 1995). The implementation of a quality program has the potential to improve not only safety, but also the processes and efficiency of the maintenance facility in a structured, continuous manner.

\section{Suggestions for Future Research}

This review discussed some of the literature centered on the interrelationship of safety and quality, briefly introduced some of the tools used to improve quality, and introduced several standards which might be applicable to the subject of the paper. There are several areas related to this topic that were not discussed or were cursorily mentioned. Additional research and discussion is suggested in the following areas:

- Cost of implementing a TQM program in a similar industry. Although the costs of certification to standards such as ISO 9000 are well documented, research of the literature and data collection via a survey instrument to determine the costs of implementing a quality program in personnel and financial terms seems appropriate for collegiate aviation.

- Effect on safety of implementing a TQM program in a similar industry. Research should be conducted either through an examination of the literature or a survey instrument -- to determine whether changes in safety, if any, resulted from the implementation of a quality program in an identified industry.

- Determine best practices for development of a quality program for collegiate aviation maintenance facilities. Research on a similar industry should be conducted to determine the most appropriate model for such a program. $\square$

\begin{abstract}
Alan J. Stozer holds an M.S. in Aeronautical Science from Embry-Riddle Aeronautical University and a B.S. in Aerospace Science from the College of the Ozarks. He is an Associate Dean and a Professor of Aviation Science at Parks College of Engineering and
\end{abstract} Aviation, Saint Louis University. 


\section{REFERENCES}

Aerospace launches new quality standard (1999, November). Quality Digest, p. 11.

Anderson, S., Daly, J., \& Johnson, M. (1999). Why finns seek ISO 9000 certification: Regulatory compliance or competitive advantage? Production and Operations Management, pp. 28-43.

Baldrige index outperforms S\&P 500 for fifth year. (1999). National Institute of Standards, Press Release 99-02.

Bravener, L. (1997). Aerospace launches AS 9000. Quality Digest.

Chittenden, F., Poutziouris, P., Mukhtar, S., (1998). Small firms and the ISO 9000 approach to quality management. International Small Business Journal, pp. 73-88.

Dreikorn, M. (1995). Aviation industry quality systems: ISO 9000 and the Federal Aviation Regulations. Milwaukee: ASQC Quality Press.

Easton, G. \& Jarrell, S. (1998). The effects of total quality management on corporate performance: An empirical investigation. Journal of Business, 253-307.

Ebrahimpour, M., Withers, B., Hikmet, N. (1997). Experiences of US- and foreign-owned firms: A new perspective on ISO 9000 implementation. International Journal of Production Research.

Federal Aviation Administration. (1999). Notice of Proposed Rulemaking, Docket No. FAA-1999-5836; Notice No. 99-09. Federal Register.

Garetson, M. (1999). A recipe for quality. Aircraft Maintenance Technology, pp. 60-62.

Juran, J., Godfrey, A. (Eds.). (1999). Juran's Quality Handbook ( $5^{\text {th }}$ Edition). New York: McGraw Hill.

Krause, T. (1993). Safety and quality: two sides of the same coin. Occupational Hazards, p. 47.

Larson, M. (1999). AS 9000 implementation: Still in the wild blue yonder. Quality, pp. 46-48.

Manzella, J. (1997). Achieving safety performance excellence through total quality management. Professional Safety, pp. 26-28.

National Institute of Standards and Technology. (1997). The Malcolm Baldrige National Quality Improvement Act of 1987 - Public Law 100-107. [On-line]. Available World Wide Web:

Peach, R. (1995). The ISO 9000 handbook ( $2^{\text {nd }}$ Edition). Fairfax, VA: Irwin.

Peterson, D. (1994). Integrating safety into total quality management. Professional Safety, p. 28.

Pollock, R. (1997). Making safety matter. Occupational Hazards. 193.

Simmons, B. \& White, M. (1999). The relationship between ISO 9000 and business performance: Does registration really matter? Journal of Managerial Issues, 330-343.

Singhal, V. \& Hendricks, K. (1999). The financial justification of TQM. Center for Quality of Management Journal, 3-16. SCSI - Southern California Safety Institute (2000). Operational Risk Management Course Description. [online]. Available:

http://www.scsi-int.com/orm.html.

Velocci, A. (1998, November). Pursuit of six sigma emerges as industry trend. Aviation Week \& Space Technology, p. 152.

Warrack, B., \& Sinha, M. (1999). Integrating safety and quality: Building to achieve excellence in the workplace. Total Quality Management, pp. 779-785.

Weinstein, M. (1996). Total quality approach to safety management. Professional Safety. 18.

Zuckerman, A. (1997). International standards desk reference: Your passport to world markets. New York: AMACOM. 
https://commons.erau.edu/jaaer/vol9/iss2/3 